\title{
Tinospora cordifolia stem supplementation in diabetic dyslipidemia: an open labelled randomized controlled trial
}

\author{
Kuhu Roy ${ }^{1}$, Rumin Shah ${ }^{2}$ and Uma Iyer ${ }^{1}$ \\ ${ }^{1}$ Department of Foods and Nutrition, Faculty of Family and Community Sciences, The \\ Maharaja Sayajirao University of Baroda, Vadodara-390007, Gujarat, India; ${ }^{2}$ Internal \\ Medicine, Vadodara-390007, Gujarat, India \\ Corresponding author: Uma Iyer, $\mathrm{PhD}$, Professor, Head, Department of Foods and \\ Nutrition, Dean, Faculty of Family and Community Sciences, The Maharaja Sayajirao \\ University of Baroda, Vadodara-390007, Gujarat, India
}

Submission Date: June 10, 2015, Acceptance date: August 28, 2015: Publication date: August 31,2015

\begin{abstract}
:
Background: Medicinal plants are powerful health promoting nutritional agents. Among the vast library of medicinal plants Tinospora cordifolia (Willd.) has been meagrely explored. It belongs to the family Menispermaceae and is a rich source of alkaloid and terpenes. It has hepatoprotective, antioxidant, immunostimulatory, hyperlipidemic, anticancer and antidiabetic properties. The stem contains berberine, palmatine, tembetarine, magnoflorine, tinosporin, tinocordifolin. The stem starch is highly nutritive and digestive. In modern medicine it is called the magical rejuvenating herb owing to its properties to cure many diseases. The stem contains higher alkaloid content than the leaves because of which it is approved for medicinal usage. With a host of phytochemical properties present in the stem, it may hold potential to manage dyslipidemia and dysglycemia, which otherwise has been proven only in pre-clinical studies.
\end{abstract}

Objective: To study the impact of tinospora cordifolia stem supplementation on the glycemic and lipemic profile of subjects with diabetic dyslipidemia.

Methods: Type 2 diabetics with dyslipidemia on oral hypoglycemic agents were enrolled. Baseline data on medical history, family history of lifestyle diseases, duration of diabetes diagnosis, drug profile, anthropometric data, dietary data and physical activity data was obtained along with a fasting blood sample for estimating high sensitivity $\mathrm{C}$ reactive protein (hs-CRP), hepatic, renal, lipid profile and glycated hemoglobin. The participants were randomized into either of the two groups; intervention group $(n=29)$ received $250 \mathrm{mg}$ of encapsulated mature stem of tinospora cordifolia pre meal twice a day along with prescribed dyslipidemic agent and control group $(n=30)$ only on dyslipidemic agents for a period of 60 days. After 60 days all the parameters were re-assessed to analyse the impact of the intervention. 
Results: Majority of the subjects in both the arms were in the 50-60 years age bracket with a similar duration of diabetes, disease and drug profile. Tinospora cordifolia supplementation led to a significant decline in waist circumference (94.7 to $94.2 \mathrm{~cm}, \mathrm{P} 0.004$ ), hip circumference $(99.9$ to $9.5 \mathrm{~cm}, \mathrm{P} 0.004)$, waist stature ratio $(0.594$ to $0.591, \mathrm{P} 0.004)$ and systolic blood pressure (132.6 to $127.1 \mathrm{mmHg}, \mathrm{P}$ 0.0017) vs. significant decline in hip circumference (100.02 to $99.7 \mathrm{~cm}, \mathrm{P} 0.01$ ) and systolic blood pressure $(134.5$ to $130.1 \mathrm{mmHg}$, $\mathrm{P}$ 0.0013) in controls. The intervention brought about a significant decline in hs-CRP (4.6 to $2.8 \mathrm{mg} / \mathrm{l}, \mathrm{P} 0.0007$ ) and the prevalence of hs-CRP $>3 \mathrm{mg} / \mathrm{l}$ declined from $65.5 \%$ to $37.9 \%$ (P 0.037). Renal and hepatic parameters remained in the normal range. Decline in HbA1c, although non-significant, was more evident in the intervention arm (7.7 to 7.5\%, P 0.09) than the controls ( 7.9 to $7.81 \%, \mathrm{P} 0.52$ ). Intervention led to significant reductions in total cholesterol, low density lipoprotein, triglycerides and very low density lipoprotein and among controls too, but of lesser intensity. The number of dyslipidemic features declined by $28.6 \%$ ( $\mathrm{P}$ 0.0036) in the intervention arm and by $19.4 \%$ in controls ( $\mathrm{P} 0.020)$. The prevalence of metabolic syndrome decreased by $13.73 \%$ from $68.9 \%$ to $55.17 \%$ in the intervention arm and reduced by $6.7 \%$ from $56.7 \%$ to $50 \%$ among controls.

Conclusion: Tinospora cordifolia stem supplementation brought about more evident changes in the lipoprotein fractions, inflammatory markers and metabolic syndrome than the controls.

Keywords: Diabetic dyslipidemia, tinospora cordifolia, lipid profile, metabolic syndrome

\section{INTRODUCTION:}

Dyslipidemia in type 2 diabetics is the root cause of macrovascular complications namely, cardiovascular disease (CVD), cerebrovascular disease and peripheral vascular disease [1]. Although it is a modifiable risk factor for CVD [2], it accounts for $70 \%$ of all deaths in this population [3]. Therefore, management of diabetic dyslipidemia warrants much attention. Statins (3-hydroxy-3-methylglutaryl coenzyme A reductase) are used as the initial therapy [4]. However, even with statin therapy the risk of CVD lurks. The desired impact is often marred by the side effects of statins [5]. This is where phytomedicines score over the modern medicine as they are of natural origin, less side effects [6, 7] and better efficiency [7, 8].

A medicinal plant with anti-diabetic and anti-dyslipidemic potential is Tinospora cordifolia (Willd.) Hook.f. \& Thomson. It belongs to the family Menispermaceae [9] and is a rich source of alkaloid and terpenes [10]. In modern medicine it is called 'the magical rejuvenating herb' [11]. The stem is highly nutritive, digestive [12] and contains; berberine, palmatine, tembetarine, magnoflorine, tinosporin, tinocordifolin [13]. The stem owing to its higher alkaloid content is approved for medicinal usage [14].

The stem extract has demonstrated antidyslipidemic activity in alloxan-induced diabetic rats [15] and streptozotocin-induced diabetic rats [16], anti-diabetic activity in streptozotocin diabetic rats [17], streptozotocin diabetic albino rats [18]. Another study on diabetes induced Wistar rats demonstrated that alcoholic stem extract of tinospora cordifolia has antidiabetic and antihyperlipidemic potential [19]. It has shown to be a better drug to regress diabeticdyslipidemia [15] and the extrapancreatic and intrapancreatic activities are postulated to impart the anti-diabetic effect [20]. With no studies available on humans after showing commendable impact on the glycemic and lipemic profile in animal models, the stem may 
hold potential to manage dyslipidemia and dysglycemia in type 2 diabetics. Hence, the study aimed to assess the impact of tinospora cordifolia stem supplementation on the glycemic and lipemic profile of subjects with diabetic dyslipidemia.

\section{MATERIALS AND METHODS:}

Type 2 diabetics with dyslipidemia on oral hypoglycemic agents (OHA) and statins were enrolled, those with secondary complications, gestational diabetes and type 1 diabetes were excluded. The participants were randomly allocated into two groups; intervention group $(n=29)$ to receive $250 \mathrm{mg}$ of encapsulated mature stem of tinospora cordifolia pre meal twice a day along with prescribed OHA and statin and control group $(n=30)$ only on OHAs and statin for a period of 60 days. Baseline data on medical history, family history of lifestyle diseases, duration of diabetes, drug profile was obtained with the help of a pre-tested questionnaire. Data on physical activity was obtained with the help of international physical activity questionnaire, short form [21]. Weight was measured to the nearest $0.1 \mathrm{~kg}$ with the help of a research grade digital weighing scale. Height was measured to the nearest $0.1 \mathrm{~cm}$ with the help of the fibre glass tape. Body mass index (BMI) was obtained by dividing weight in kilograms by the square of height in meters and assessed based on the Asia Pacific classification [22]. Waist circumference (WC) was measured at the level of the umbilicus and hip circumference (HC) was measured at the point of maximum protruding part of the buttocks with the help of a fibreglass tape. Blood pressure was recorded with a mercury sphygmomanometer. A 12 hours fasting blood sample was obtained for estimating high sensitivity $\mathrm{C}$ reactive protein (hs-CRP), hepatic, renal, lipid profile and glycated hemoglobin through standard laboratory procedures. Diabetic dyslipidemia was defined as the presence of one or more than one of the following lipid aberrations: total cholesterol (TC), triglycerides, low density lipoprotein cholesterol (LDL-C) and high density lipoprotein cholesterol (HDLC) [23]. Metabolic syndrome was defined as abdominal obesity plus two or more of the following risk factors: fasting glucose $>100 \mathrm{mg} / \mathrm{dl}$ or previously diagnosed type 2 diabetes, blood pressure $>130 / 85 \mathrm{mmHg}$, triglycerides $>150 \mathrm{mg} / \mathrm{dl}$ or on specific treatment for the said condition, HDL-C $<40 \mathrm{mg} / \mathrm{dl}$ in case of men and $<50 \mathrm{mg} / \mathrm{dl}$ in case of women, WC $\geq 90 \mathrm{~cm}$ in men and $\geq 80 \mathrm{~cm}$ in women [24]. After 60 days all the parameters were re-assessed to analyse the impact of the intervention.

Supplementation dosage: A dosage of $500 \mathrm{mg}$ per day is considered to be safe for consumption [25]. 250 miligrams of mature stem extact of tinospora cordifolia was encapsulated in gelatine coated capsules. Very less information on toxicity is available [26]. From the nutrient drug interaction perspective, it has a potential basis for clinically desirable drug interactions [27] because of which it is considered desirable as a supportive drug for glycemic control, avert complications and alleviate side effects of synthetic drugs [20].

Ethics: The study was approved by the Institutional Medical Ethics Committee of the Department of Foods and Nutrition, Faculty of Family and Community Sciences, The Maharaja Sayajirao University of Baroda (IECHR/2013/5). Written and informed consent was obtained from all the subjects.

Statistical analysis: The data was entered in Microsoft Excel 2007 and analysed in statistical package for social sciences 20 (SPSS, Chicago, IL, USA) and Epi Info 3.4.1. The continuous 
variables were presented as mean (student $t$ test) \pm standard deviation. Frequencies and percentages were used to derive the quantification of responses and subjected to Chi square test to determine an association between two independent nominal random variables. Results were considered to be statistically significant with a 2 tailed $\mathrm{p}$ value of $<0.05^{*}, \mathrm{P}<0.01^{* *}$ and $\mathrm{P}<0.001 * * *$. To assess the impact of intervention, paired t-test was used.

\section{RESULTS:}

General Profile: The age, duration of diabetes and family history of non-communicable diseases was similar in both the arms. Majority were in the 50 to 60 years age bracket. Subjects had a similar drug profile as only those on OHAs and statins were enrolled. About $55.5 \%$ in the intervention arm and $43.3 \%$ controls had clinically confirmed hypertension. At pre and post intervention and between groups subjects had non-significant moderate physical activity profile.

Impact on Anthropometric and Blood Pressure Profile: Supplementation led to a significant decline in WC (94.7 to $94.2 \mathrm{~cm}, \mathrm{P} 0.004,0.52 \%)$, HC (99.9 to $9.5 \mathrm{~cm}, \mathrm{P} 0.004$, $0.4 \%)$, waist stature ratio $(0.594$ to $0.591, \mathrm{P} 0.004,0.5 \%)$ and systolic blood pressure (132.6 to $127.1 \mathrm{mmHg}, \mathrm{P} 0.0017,4.1 \%)$ vs. significant decline in $\mathrm{HC}(100.02$ to $99.7 \mathrm{~cm}, \mathrm{P} 0.01$, $0.31 \%$ ) and systolic blood pressure (134.5 to $130.1 \mathrm{mmHg}, \mathrm{P} 0.0013,3.3 \%$ ) in controls (table 1). Subjects with a normal BMI increased (13.7\% to $17.2 \%)$ and the prevalence of overweight ( $24.1 \%$ to $20.6 \%$ ), elevated WC (86.2\% to $82.7 \%$ ) and elevated WSR $(79.3 \%$ to $72.4 \%$ ) declined in the experimental arm post intervention. Nutritional status remained unaltered in the controls.

Impact on biochemical profile: Supplementation led to a significant decline in uric acid from 5.2 to $4.6 \mathrm{mg} / \mathrm{dl}$ (P 0.007), and was also found to be significantly lower than the controls (5.7 to $4.6 \mathrm{mg} / \mathrm{dl}, \mathrm{P}$ 0.0018) (table 1 ). Hs-CRP declined significantly from 4.6-2.8mg/l (P 0.0007 ) and consequently did the prevalence of high risk CVD by $27.6 \%$ (P 0.03). Blood urea nitrogen and creatinine declined non-significantly and bilirubin total (P 0.021) and bilirubin indirect (P 0.047) increased significantly in the control arm. Alkaline phosphatase declined significantly in the experimental arm by $11.4 \%$ from $96.2 \mathrm{U} / \mathrm{L}$ to $85.2 \mathrm{U} / \mathrm{L}$ (P 0.0013) and other liver enzymes (SGPT, SGOT, GGT) reduced non-significantly. HbA1c was similar at baseline in both the arms. A non-significant decline post intervention was more evident in the experimental arm (by 2.6\%, from $7.7 \%$ to $7.5 \%$, P 0.09) than the control arm (by $1.1 \%$, from $7.9 \%$ to $7.81 \%$, P 0.52). Average blood glucose (ABG) also declined in both the arms and reached a near significant decline $(\mathrm{P}$ 0.06) in the experimental arm. The prevalence of normoglycemia (HbA1c <6\%) declined in the control arm (from $10 \%$ to $6.6 \%$ ) and shot up in the experimental arm (from $6.8 \%$ to $10.3 \%$ ). The prevalence of unsatisfactory glycemia (HbA1c >8\%) declined in both the arms after the intervention with drop more evident in the control arm (from $46.6 \%$ to $36.6 \%$ ) than the experimental arm (from $34.4 \%$ to $27.5 \%$ ). Intervention led to significant reductions in TC (by $14.5 \%, 208.3$ to $178 \mathrm{mg} / \mathrm{dl}, \mathrm{P} 0.0008$ ), LDL-C (by $13.6 \%, 122.4$ to $105.8 \mathrm{mg} / \mathrm{dl}, \mathrm{P}$ 0.0028), triglycerides (by 14.9\%, 146.1 to $124.3 \mathrm{mg} / \mathrm{dl}, \mathrm{P}$ 0.036) and very low density lipoprotein cholesterol (VLDL-C) (by 18.3\%, 28.9 to $23.6 \mathrm{mg} / \mathrm{dl}, \mathrm{P} 0.003$ ). The controls also had a significant reduction in TC (by $6.8 \%, 188.2$ to $175.4 \mathrm{mg} / \mathrm{dl}$, P 0.009), LDL-C (by $13.4 \%, 112.6$ to $97.5 \mathrm{mg} / \mathrm{dl}, \mathrm{P} 0.0012$ ), triglycerides (by $16 \%, 154.6$ to $129.9 \mathrm{mg} / \mathrm{dl}, \mathrm{P} 0.0017$ ) and VLDL-C (by $17.4 \%, 30.4$ to $25.1 \mathrm{mg} / \mathrm{dl}, \mathrm{P} 0.010$ ). 
The average number of dyslipidemic features declined by $28.6 \%$ ( $\mathrm{P}$ 0.0036) in the intervention arm and by $19.4 \%$ in controls (P 0.020).

Impact on Prevalence of Metabolic Syndrome: The prevalence of metabolic syndrome decreased by $13.73 \%$ from $68.9 \%$ to $55.17 \%$ in the intervention arm as a result of decline in the number of features of metabolic syndrome (3.2 to $2.86, \mathrm{P} 0.059)$ and reduced by only $6.7 \%$ from $56.7 \%$ to $50 \%$ among controls (table 1 ).

Table 1: Impact Of Tinospora Cordifolia Supplementation On Lipid Profile, Uric Acid, HsCrp, Glycemic Profile And Metabolic Syndrome Of Type 2 Diabetics With Dyslipidemia (Mean \pm SD)

\begin{tabular}{|c|c|c|c|c|}
\hline Variables & Stage & $\begin{array}{l}\text { Control Group } \\
(\mathrm{N}=30)\end{array}$ & $\begin{array}{l}\text { Experimental Group } \\
(\mathrm{N}=29)\end{array}$ & P Value \\
\hline \multirow[t]{3}{*}{$\mathrm{TC}(\mathrm{mg} / \mathrm{dl})$} & Pre & $188.2 \pm 38.2$ & $208.3 \pm 41.9$ & 0.058 \\
\hline & Post & $175.4 \pm 37.8$ & $178 \pm 49.2$ & 0.82 \\
\hline & Paired t & $0.009 * *(\downarrow 6.8 \%)$ & $0.0008 * * *(\downarrow 14.5 \%)$ & \\
\hline \multirow[t]{3}{*}{ HDL-C (mg/dl) } & Pre & $45.4 \pm 9.3$ & $45.6 \pm 10.2$ & 0.93 \\
\hline & Post & $46.7 \pm 11.1$ & $45.3 \pm 11.08$ & 0.63 \\
\hline & Paired $\mathrm{t}$ & $0.25(\uparrow 2.9 \%)$ & $0.80(\downarrow 0.65 \%)$ & \\
\hline \multirow[t]{3}{*}{ LDL-C `(mg/dl) } & Pre & $112.6 \pm 31.7$ & $122.4 \pm 38.01$ & 0.28 \\
\hline & Post & $97.5 \pm 26.1$ & $105.8 \pm 37.1$ & 0.33 \\
\hline & Paired $t$ & $0.0012 * *(\downarrow 13.4 \%)$ & $0.0028 * *(\downarrow 13.6 \%)$ & \\
\hline \multirow[t]{3}{*}{ Triglycerides (mg/dl) } & Pre & $154.6 \pm 65.06$ & $146.1 \pm 75.1$ & 0.64 \\
\hline & Post & $129.9 \pm 48.1$ & $124.3 \pm 45.8$ & 0.64 \\
\hline & Paired $\mathrm{t}$ & $0.0017 * *(\downarrow 16 \%)$ & $0.036 *(\downarrow 14.9 \%)$ & \\
\hline \multirow[t]{3}{*}{ VLDL $-\mathrm{C}(\mathrm{mg} / \mathrm{dl})$} & Pre & $30.4 \pm 12.7$ & $28.9 \pm 15.1$ & 0.68 \\
\hline & Post & $25.1 \pm 10.8$ & $23.6 \pm 9.7$ & 0.58 \\
\hline & Paired t & $0.010 * *(\downarrow 17.4 \%)$ & $0.003 * *(\downarrow 18.3 \%)$ & \\
\hline \multirow{3}{*}{$\begin{array}{l}\text { No. of dyslipidemic } \\
\text { features }\end{array}$} & Pre & $2.06 \pm 1.11$ & $2.27 \pm 1.27$ & 0.50 \\
\hline & Post & $1.66 \pm 0.99$ & $1.62 \pm 1.17$ & 0.87 \\
\hline & Paired $\mathrm{t}$ & $0.020 *(\downarrow 19.4 \%)$ & $0.0036 * *(\downarrow 28.6 \%)$ & \\
\hline \multirow[t]{3}{*}{ Hs-CRP (mg/l) } & Pre & $4.3 \pm 3.5$ & $4.6 \pm 3.2$ & 0.72 \\
\hline & Post & $3.4 \pm 3.6$ & $2.8 \pm 2.4$ & 0.44 \\
\hline & Paired $\mathrm{t}$ & $0.10(\downarrow 20.9 \%)$ & $0.0007 * * *(\downarrow 39.1 \%)$ & \\
\hline \multirow[t]{3}{*}{ Uric acid $(\mathrm{mg} / \mathrm{dl})$} & Pre & $5.6 \pm 1.2$ & $5.2 \pm 1.4$ & 0.29 \\
\hline & Post & $5.7 \pm 1.1$ & $4.6 \pm 1.2$ & $0.0018 * *$ \\
\hline & Paired $\mathrm{t}$ & $0.87(\uparrow 1.8 \%)$ & $0.007 * *(\downarrow 11.5 \%)$ & \\
\hline \multirow[t]{3}{*}{ HbA1c (\%) } & Pre & $7.9 \pm 1.7$ & $7.7 \pm 1.5$ & 0.55 \\
\hline & Post & $7.81 \pm 1.69$ & $7.5 \pm 1.5$ & 0.50 \\
\hline & Paired t & $0.52(\downarrow 1.1 \%)$ & $0.09(\downarrow 2.6 \%)$ & \\
\hline \multirow[t]{3}{*}{$\mathrm{ABG}(\mathrm{mg} / \mathrm{dl})$} & Pre & $181.2 \pm 53.5$ & $176.2 \pm 44.9$ & 0.57 \\
\hline & Post & $176.9 \pm 49.6$ & $168.6 \pm 46.5$ & 0.51 \\
\hline & Paired t & $0.51(\downarrow 2.4 \%)$ & $0.06(\downarrow 4.3 \%)$ & \\
\hline \multirow{3}{*}{$\begin{array}{l}\text { Metabolic syndrome } \\
(\%)\end{array}$} & Pre & $17(56.7)$ & $20(68.9)$ & 0.33 \\
\hline & Post & $15(50)$ & $16(55.17)$ & 0.69 \\
\hline & $\chi^{2}$ & 0.60 & 0.28 & \\
\hline \multirow{3}{*}{$\begin{array}{l}\text { No. of features of } \\
\text { metabolic syndrome }\end{array}$} & Pre & $3.13 \pm 1.1$ & $3.2 \pm 1.01$ & 0.89 \\
\hline & Post & $3.06 \pm 0.90$ & $2.86 \pm 1.15$ & 0.71 \\
\hline & Paired $\mathrm{t}$ & $0.62(\downarrow 2.2 \%)$ & $0.059(\downarrow 10.6 \%)$ & \\
\hline
\end{tabular}




\section{DISCUSSION:}

Though animal models have demonstrated anti-diabetic and anti-dyslipidemic potential of tinospora cordifolia stem extract, there are no human studies to corroborate the same. With the aim of studying the impact of tinospora cordifolia stem supplementation on dyslipidemia and dysglycemia, type 2 diabetics on OHAs and statin were enrolled from a diabetic clinic. They were randomly assigned into two groups, experimental arm $(n=29)$ that received tinospora cordifolia stem capsules ( $250 \mathrm{mg}$ twice daily pre meal) along with statin and OHAs and control arm received statin and OHAs for duration of 60 days.

The supplementation demonstrated anti-inflammatory role of tinospora cordifolia stem as the hs-CRP and uric acid declined significantly and also significantly brought down the prevalence of high risk CVD. Anti-inflammatory activity is confirmed by the presence of cardiac glycosides. The alkaloids too are known to impart anti-inflammatory and anti-oxidant effect [28].

Though statistically non-significant, drop in $\mathrm{HbA1c}$ and $\mathrm{ABG}$ was greater in the experimental arm. This explains the possible anti-diabetic function of tinospora cordifolia stem owing to the presence of alkaloids (Magnoflorine, Palmetine, Jatrorrhizine) [29], tannins, cardiac glycosides, saponins, steroids and flavonoids [30]. Further evidence comes from a study wherein hexane, ethyl acetate and methanol Tinospora cordifolia stem extract at a dose of $250 \mathrm{mg} / \mathrm{kg}$ b.w. for a period of 100 days had an antidiabetic effect which reduced blood sugar level in streptozotocin induced diabetic rats. The supplementation also significantly reversed reduced glucokinase and increased glucose-6-phoaphatase activity and decreased the HbA1c [17].

Streptozotocin diabetic albino rats benefited from different dosages $(200$ and $400 \mathrm{mg} / \mathrm{kg}$ b.w.) of Tinospora cordifolia (Willd.) stem extracts (both aqueous and alcoholic) as it had significant anti-diabetic activity in diabetic animals and had an efficacy of $40 \%$ to $80 \%$ compared to insulin. Because the extract did not cause any increase in serum insulin levels or regeneration of pancreatic $\beta$ cells but caused increased hepatic glycogen synthase and decreased glycogen phosphorylase activity, it was postulated by the authors that tinospora cordifolia maybe acting as an anti-hyperglycemic drug through some peripheral mechanisms, such as increasing the glycogen storage in the liver or by decreasing the activity of glycogen phosphorylase, thereby retarding or preventing glucose release from the liver [18]. Another think tank is of the opinion that the biological anti-diabetic mechanism is by way of promotion of insulin secretion by inhibiting gluconeogenesis and glycogenolysis by the stem [29]. Its extra-pancreatic and intra-pancreatic activities have the positive effect on the glycemic status [20].

Advantageously, tinospora cordifolia administration along with metformin has shown beneficial pharmacokinetic and pharmacodynamic interaction leading to enhancing antihyperglycemic and antihyperlipidemic activities [31]. Infact, berberine, the alkaloid present in the stem has shown to boost the effects of metformin and 2,4-thiazolidinedione [32] and is known to lower elevated blood glucose as effectively as metformin [33]. This could be one of the possible reasons why the intervention arm subjects had a more evident anti-diabetic profile than the controls, although a higher dosage or a longer duration of the trial could have brought about significant changes in the glycemic profile.

TC and VLDL-C reduced more prominently and the reduction in LDL-C was similar and in triglycerides was marginally lower in the intervention arm. The stem is also known to contain saponins which might have bound cholesterol in the present study [34]. Berberine by 
adenosine monophosphate-activated protein kinase activation is also known to decrease the cholesterol level [33]. In totality, the number of features of dyslipidemia reduced significantly with tinospora cordifolia supplementation. To support that, the stem extract has shown to normalize lipid metabolism alterations caused by diabetes mellitus in streptozotocin-induced diabetic rats [16]. The extracts may not have the similar mechanism of action by interfering HMG-CoA reductase and may be due to the interference of cholesterol with residues at the absorption site in gastrointestional tract since they were co-administered. There was a significant decrease in lipids and HDL-C remained unaffected in Sprague dawley rats that were induced with hyperlipidemia but were treated with methanolic extract of tinospora cordifolia stem at $400 \mathrm{mg} \mathrm{kg}-1$ dose. The reduction was found to be significant when compared with atorvastatin, though of lesser intensity [35].

The antidyslipidemic activity of tinospora cordifolia stem extract has also been demonstrated in alloxan-induced $(150 \mathrm{mg} / \mathrm{kg}$ body wt.) diabetic rats who were (dyslipidemic) orally fed stem extract (500 mg/kg body weight) for 15 days that resulted in significant decrease in plasma glucose, HbA1c lipid peroxide, total lipid and FFA. The extract also had an anti-diabetic effect but it was lesser in intensity than glibenclamide. Antidyslipidemic activity of the stem may be partly due to presence of the alkaloids [15].

Another study on diabetes induced Wistar rats demonstrated that alcoholic stem extract of tinospora cordifolia has antidiabetic and antihyperlipidemic potential [19]. Another evidence of antidyslipidemic activity of the tinospora cordifolia stem extract comes from a study on alloxan induced diabetic rats that were orally administered $500 \mathrm{mg} / \mathrm{kg}$ bw stem extract for 30 days. Blood glucose, plasma lipids reduced significantly and post heparin lipoprotein lipase activity was reactivated. Importantly, the extract inhibited the generation of super oxide anions and hydroxyl radicals, in both enzymic and non-enzymic systems in vitro [36]. The tinospora cordifolia stem also demonstrates free radical scavenging activity [37] because of which it has potential to be used in food systems as an antioxidant and in biological systems as a nutraceutical or a dietary supplement [38]. However, the antioxidant activity was not estimated in the present study.

Metabolic syndrome reduced more prominently in intervention arm than controls. This could have been possibly due to two reasons. One, anti-hypertensive role of tinospora cordifolia was evident as it brought down the systolic blood pressure more prominently than the controls, who had a similar anti-hypertensive drug profile. Secondly, elevated WC was the most common feature of the metabolic syndrome in the present study. However, the supplementation brought down the mean WC. These two factors in congregation reduced the prevalence of metabolic syndrome more prominently in the intervention arm than the controls. In totality, a reduction in the lipid profile together with reduction in the prevalence of metabolic syndrome signifies reduced risk of adverse cardiac events. Berberine has been documented to improve hepatic metabolism during IR and MS and by adenosine monophosphate-activated protein kinase activation maintains the blood pressure [33].

To our knowledge, this is the first clinical trial to document the impact of tinospora cordifolia stem in the management of diabetic dyslipidemia and dysglycemia. The compliance in the study was assumed to be $100 \%$ as empty tablet containers were returned on completion of the study period. As no adverse effects were reported in the subjects, other than a single drop out, the dosage is being presumed to have been well within the tolerable limits. This is further corroborated as the surrogate laboratory safety biomarkers remained well within the normal limit. Having the benefit of being desirable as a supportive glycemic 
drug $[18,20]$ and known to boost the effect of OHAs [32], tinospora cordifolia stem can be an adjunct therapy to deal with the dual problems of dyslipidemia and dysglycemia. However, the study had certain limitations to it. It had a relatively smaller sample size and was of shorter duration.

A dose of $500 \mathrm{mg}$ tinospora cordifolia stem over a two months period brought about more evident changes in the lipoprotein fractions, HbAlc, inflammatory markers and metabolic syndrome. With no major or minor adverse events reported, it only sets ground for conduction of aggressive clinical trials to further validate the first set of findings on humans of the impact of tinospora cordifolia in the management of dyslipidemia and dysglycemia in patients with type 2 diabetes.

Abbreviations: CVD, cardiovascular disease; OHA, oral hypoglycaemic agent; BMI, body mass index; WC, waist circumference; HS-CRP, high sensitivity $\mathrm{C}$ reactive protein, TC, total cholesterol; LDL-C, low density lipoprotein cholesterol, HDL-C, high density lipoprotein cholesterol, VLDL-C, very low density lipoprotein cholesterol.

Author contributions: KR did literature search, data acquisition, computation and analysis of the data and prepared the manuscript. UI conceptualized and designed the study and reviewed the manuscript. RS provided patients and reviewed the manuscript.

Acknowledgement: The authors would like to thank the University Grant Commission (UGC) for providing senior research fellowship to the research scholar, Ms. Kuhu Roy for the study. Part of the data is from the Ph.D. dissertation of Ms. Kuhu Roy, which will be submitted to the Maharaja Sayajirao University of Baroda, Vadodara, Gujarat, India.

\section{Conflict of Interest: None}

\section{REFERENCES}

1. Farmer, J.A. 2008. Diabetic dyslipidemia and atherosclerosis: evidence from clinical trials. Curr Diab Rep. 8:71-77.

2. Saydah, S.H., Fradkin, J., Cowie, C.C. 2004. Poor control of risk factors for vascular disease among adults with previously diagnosed diabetes. JAMA. 291:335-342.

3. Kershnar, A.K., Daniels, S.R., Imperatore, G., Pala, S.L., Petitti, D.B., Pettitt, D.J., Marcovina, S., Dolan, L.M., Hamman, R.F., Liese, A.D., Pihoker, C., Rodriguez, B.L. 2006. Lipid abnormalities are prevalent in youth with type 1 and type 2 diabetes: the SEARCH for Diabetes in Youth Study. J Pediatr, 149: 314-319.

4. American Diabetes Association. 2003. Management of dyslipidemia in adults with diabetes (Position Statement). Diabetes Care. 26: S83-S86.

5. Vijayaraghavan K. 2010. Treatment of dyslipidemia in patients with type 2 diabetes. Lipids in Health and Disease. 9:144.

6. Modak, M., Dixit, P., Londhe, J., Ghaskadbi, S., Devasagayam, T.P.A. 2007. Indian herbs and herbal drugs used for the treatment of diabetes. Journal of Clinical Biochemistry and Nutrition, 40: 163-173.

7. Pandey, M.M, Rastogi, S., Rawat, A.K.S. 2013. Indian Traditional Ayurvedic System of Medicine and Nutritional Supplementation. Evidence-Based Complementary and Alternative Medicine. Article ID 376327, 12 pages. 
8. Konda, V.G.R., Madhavi, E., Ruckmani, A., Venkataramana, Y. 2013. A review on medicinal plants with potential hypolipidemic activity.Int J Pharm Bio Sci. 4:729-40.

9. Sankhala, L.N., Saini, R.K., Saini, B.S. 2012. A review on chemical and biological properties of Tinospora cordifolia, IJMAP 2(2) 340-344.

10. Sharma, A., Gupta A, Singh S, Batra A. 2010. Tinospora cordifolia (Willd.) Hook. F. and Thomson - A plant with immense economic potential. Journal of Chemical and Pharmaceutical Research. 2: 327-33.

11. Singh, S.S., Pandey, S.C., Srivastava, S., Gupta, V.S., Patro, B., Ghosh, A.C. 2003. Chemistry and medicinal properties of Tinospora cordifolia (Guduchi). Indian Journal of Pharmacology.35: 83-91.

12. Sinha, K., Mishra, N.P., Singh, J., Khanuja, S.P.S. 2004. Tinospora cordifolia (Guduchi), a reservoir plant for therapeutic applications: A review. Indian Journal of Traditional Knowledge. 3: 257-70.

13. Kumar, S., Verma, N.S., Pande, D., Srivastava, P.S. 2000. In vitro regeneration and screening of berberine in Tinospora cordifolia. J Med Arom Plant Sci ;22:61.

14. The Ayurvedic Pharmacopoeia of India. 2011. New Delhi: Department Of AYUSH, Ministry of Health and FW. 1 (1) 53-5.

15. Chandra, A., Sabharwal, R., Chander, R., Mahdi, F., Mahdi, A.A. 2013. Effect of Some Indian Herbs on Dyslipidemia in Streptozotocin Induced Diabetic Rats, Intern J Med Dental Sci. 2: 33.

16. Nagaraja, P.K., Kammar, K.F., Sheela, D.R. 2008. Efficacy of Tinospora cordifolia (Willd.) extracts on blood lipid profile in streptozotocin diabetic rats. Is it beneficial to the heart? Biomed Res. 19: 92-96.

17. Rajalakshmi, M., Eliza, J., Priya, C.E., Nirmala, A., Daisy, P. 2009. Anti-diabetic properties of Tinospora cordifolia stem extracts on streptozotocin- induced diabetic rats. Afr. J. Pharm. Pharmacol. 3(5): 171-180.

18. Puranik, N., Kammar, K.F., Devi, S. 2010. Anti-diabetic activity of Tinospora cordifolia (Willd.) in streptozotocin diabetic rats; does it act like sulfonylureas?. Turk J Med Sci. 40 (2): 265-270.

19. Chandavar, S.S., Naik, V.R., Prakash, R., Fahmi, S.M. 2012. Fractions of Tinospora cordifolia stem extract demonstrate insulin secreting activity in diabetes induced Wistar rats. Journal of Pharmacy Research. 5 (3): 1424-1427.

20. Sharma, R., Amin, H., Galib., Prajapati, P.K. 2015. Antidiabetic claims of Tinospora cordifolia (Willd.) Miers: critical appraisal and role in therapy Asian Pac J Trop Biomed. 5(1): 68-78.

21. Guidelines for data processing and analysis of the international physical activity questionnaire (IPAQ)- short and long forms. 2005.

22. WHO Expert Consultation. Appropriate body-mass index for Asian populations and its implications for policy and intervention strategies. 2004. Lancet. 363: 157-63.

23. Third report of the NCEP expert Panel on detection, evaluation, and treatment of High blood cholesterol in adults (ATP III). 2002. NIH publication No. 02-5215.

24. The IDF consensus worldwide definition of the metabolic syndrome. 2006. International Diabetes Federation (IDF). 366:1059-62.

25. Karkal, Y.R., Bairy, L.K. 2007. Safety of aqueous extract of Tinospora cordifolia in healthy volunteers: A double blind randomized placebo controlled study. Iranian Journal of Pharmacology and Therapeutics. 6: 59-61. 
26. Gupta, A.K., Gupta, N., Sharma, M. 2003. Indian Council of Medical Research. Quality standards of Indian medicinal plants. New Delhi: Indian Council of Medical Research. 1:212.

27. Lather, A., Gupta, V., Bansal, P., Sahu, M., Sachdeva, K., Ghaiye, P. 2011. An Ayurvedic polyherbal formulation Kaishore Guggulu: a review. Int J Pharm Biol. 2(1): 497-503.

28. Nasreen, S., Radha, R., Jayashree, N., Selvaraj, B., Rajendran, A. 2010. Assessment Of Quality Of Tinospora Cordifolia (Willd.) Miers. (Menispermaceae): Pharmacognostical And Phyto - Physicochemical Profile. Pharmacie Globale (IJCP), $1(5) ; 1-4$.

29. Patel, M.B., Mishra, S. 2011. Hypoglycemic activity of alkaloidal fraction of T. cordifolia. Phytomedicine. 18:1045-52.

30. Zinjarde, S.S., Bhargava, S.Y., Kumar, A.R. 2011. Potent $\alpha$-amylase inhibitory activity of Indian Ayurvedic medicinal plants. BMC Complement Altern Med. 11:1.

31. Patwardhan, B. 2012. The quest for evidence-based Ayurveda: lessons learned. Curr Sci. 102(10): 1406-1417.

32. Prabhakar, P.K., Doble, M. 2009. Synergistic effect of phytochemicals in combination with hypoglycemic drugs on glucose uptake in myotubes. Phytomedicine. 16(12): 1119-1126.

33. Sharma, A., Batra, A. 2013. Berberine a novel antidiabetic drug. Int J Res Rev Pharm Appl Sci. 3(2): 216-230.

34. Okwu, D.E. 2004. Phytochemicals and vitamin content of indigenous species of southeastern Nigeria. J.Sustain. Agric. Environ., 6(1): 30-37.

35. Parveen, T.D., Nyamathulla, S. 2011. Antihyperlipidemic Activity of the Methanolic extract from the Stems of Tinospora cordifolia on Sprague dawley rats. Der Pharmacia Sinica. 2 (1): 104-109.

36. Kumar, V. 2015. Antidyslipidemic and Antioxidant Activities of Tinospora cordifolia Stem Extract in Alloxan Induced Diabetic Rats. Indian Journal of Clinical Biochemistry. DOI 10.1007/s12291-015-0485-1.

37. Upadhyay, N., Ganie, S.A., Agnihotri, R.K., Sharma, R. 2013. Studies on Antioxidant Activity and Total Phenolic Content of Tinospora cordifolia (Miers.) Stem Using in Vitro Models. American Journal of Phytomedicine and Clinical Therapeutics. 1 (8): 617-627.

38. Kumar, A., Kumar, M., Dandapat, S., Sinha, M.P. 2013. Antioxidant Activity And Pharmacological Screening Of Tinospora Cordifolia (Thunb.) The Bioscan. 8(2): 689-693. 